\title{
"Racialização" das Políticas de Saúde? (nota sobre as políticas de saúde para as populações negra e indígena)
}

\section{"Racialization" of Health Policies? (notes on health policies for the black and indigenous populations)}

\section{István van Deursen Varga}

Médico. Doutor (pós-doutorado) em Saúde Pública pela Faculdade de Saúde Pública da Universidade de São Paulo. Coordenador

do Mestrado em Saúde e Ambiente da Universidade Federal do Maranhão.

Endereço: Coordenação do Mestrado em Saúde e Ambiente - Madre Deus. Praça Madre Deus, 2, $2^{\circ}$ andar, cep 65025-560, São Luís, MA, Brasil.

E-mail: ivarga®uol.com.br

\section{Resumo}

Este trabalho relata debate ocorrido em reunião do Conselho Estadual de Saúde do Maranhão, acerca da oportunidade e da conveniência de oferta, para 2 turmas, de curso de Especialização (36o h.) em Saúde da Mulher Negra pelo Mestrado em Saúde e Ambiente da Universidade Federal do Maranhão. Contextualiza-se este episódio entre os debates sobre as políticas de promoção da igualdade racial, atualmente em curso, em âmbito nacional.

Palavras-chave: Saúde da mulher negra; Políticas de promoção da igualdade racial. 


\section{Abstract}

This paper reports a debate occurred during a meeting of the State Health Council of Maranhão, regarding the opportunity and convenience of the offer, to 2 classes, of the Specialization course (360 hours) in Black Women's Health by the Master's Program in Health and Environment of the Federal University of Maranhão. This episode is contextualized among the debates about racial equality promotion policies which are currently taking place in Brazil.

Keywords: Black Women's Health; Racial Equality Promotion Policies.
É importante notar as diferenças entre as atitudes e as respostas à perspectiva da instituição de uma política nacional de saúde da população negra (e dos passos que vêm sendo dados para operacionalizá-la), em relação às que vieram a público diante da perspectiva da instituição de uma política nacional de saúde indígena, a partir de $1986^{1}$, por parte das corporações profissionais do campo da Saúde, das Ciências Sociais, e dos futuros gestores do Sistema Único de Saúde, na época também em gestação.

Notar, em primeiro lugar, que, à época, após a realização da I Conferência Nacional de Proteção à Saúde do Índio - considerada, aqui, marco institucional do nascedouro da política nacional de saúde indígena -, não se registraram críticas e manifestações públicas, de repercussão tão significativa, alertando para uma provável "racialização" das políticas de saúde e das políticas públicas daí decorrentes. Esta, no entanto, tem sido uma das críticas atualmente mais recorrentes na grande imprensa e na mídia especializada e alardeada pelos que têm questionado ou mesmo se oposto explicitamente ao estabelecimento e à operacionalização de uma política de saúde (e demais políticas públicas) específica para a população negra, desencadeando um amplo e intenso debate público.

Pretendemos abordar e discutir com maior profundidade essa diferença de atitudes, em artigo a ser publicado.

Limitamo-nos, aqui, a um breve relato sobre uma das intercorrências deste debate no Maranhão (um dos estados de maior concentração de população negra do país): a discussão, no Conselho Estadual de Saúde, da proposta de oferta de um curso de especialização em Saúde da Mulher Negra, pelo Mestrado em Saúde e Ambiente da Universidade Federal do Maranhão (com financiamento da Área Técnica de Saúde da Mulher, do Ministério da Saúde), em 7 de agosto de 2006.

Quando apresentamos a proposta, chamamos a atenção dos conselheiros para algumas especificidades de certas nosologias que acometem de modo bastante diferenciado a população negra:

- especificidades genéticas: caso da anemia falciforme e da deficiência da glicose-6-fosfato desidrogenase;

1 Quando da realização da VIII Conferência Nacional de Saúde, e da I Conferência Nacional de Proteção à Saúde do Índio (realizada segundo deliberação daquela). 
- especificidades clínicas: caso da hipertensão arterial sistêmica e do diabetes, cujos quadros mais graves, e de maior resistência aos protocolos terapêuticos, são bem mais freqüentes nesta população;

- especificidades sociais: em decorrência da histórica marginalização, das piores condições de vida e do racismo a que a população negra é submetida há mais de cinco séculos, algumas das consideradas endemias "negligenciadas", como a tuberculose, bem como a violência policial e o mau-atendimento nos serviços de saúde, por exemplo.

Não pretendíamos, de forma alguma, estabelecer uma nova especialidade no campo da saúde, mas apenas oferecer respostas, em caráter emergencial e provisório (uma vez que prevíamos a oferta do curso para apenas duas turmas), a uma das mais graves e grandes demandas sociais no estado.

Entre os argumentos dos conselheiros (todos médicos) que, de início, manifestaram-se contrariamente à proposta, o mais unânime foi o de que qualquer hematologista competente, por exemplo, saberia diagnosticar e conduzir adequadamente um caso de anemia falciforme, não se justificando, portanto, propostas de formação de profissionais voltados especificamente à atenção à saúde da população negra.

Nosso contra-argumento foi indagar aos conselheiros se eles tinham conhecimento do número de hematologistas disponíveis na rede de serviços públicos de saúde no estado, e de como estavam distribuídos entre os mesmos. Como tardasse resposta objetiva à pergunta, tomamos a iniciativa de indicá-la: muito provavelmente, a grande maioria dos hematologistas em atividade no Maranhão concentra-se em São Luís, não estando disponíveis nos municípios mais pobres (e de maior concentração de população negra) do interior - com o que, em tese, todos concordaram.

Nosso argumento final, que parece ter sido decisivo para a aprovação da proposta pelo Conselho Estadual de Saúde do Maranhão, consistiu no relato de que, apesar de termos tido a oportunidade de nos graduar num dos cursos de Medicina de melhor reputação no país, não tivemos a oportunidade de acompanhar pacientes acometidos por essa nosologia em nosso internato.

Para não enveredar na discussão sobre a quais categorias e/ou subcategorias profissionais caberiam competências específicas do atendimento destes ca- sos (que não nos interessava enfocar no momento), concluímos afirmando que, enquanto a rede de serviços públicos de saúde no estado não dispusesse de número suficiente dos especialistas citados, por exemplo, para atender a essas demandas, em sua real dimensão, clínicos gerais e demais profissionais de saúde deveriam ser capacitados, em ritmo emergencial, para, ao menos, saber reconhecê-las, tratá-las e, quando necessário, referi-las adequadamente; essa seria a principal justificativa da proposta do curso.

De nossa parte, entendemos que, como o racismo e a discriminação racial foram instituídos pelos Estados coloniais (a partir de conceitos elaborados em suas Igrejas e Academias), como instrumento de suas próprias políticas coloniais, e foi reificado pelos Estados (monárquicos e republicanos) que os sucederam nos territórios colonizados, caso do Brasil, sua superação também deve ser objeto de políticas de Estado.

Como "o objetivo central" da Política Nacional de Promoção da Igualdade Racial (PNPIR) e da Secretaria Especial de Políticas de Promoção da Igualdade Racial, da Presidência da República (SEPPIR) “... consiste em reduzir as desigualdades raciais no Brasil, com ênfase na população negra." (cf. "PNPIR" /"objetivos" em http:/ /www.planalto.gov.br/seppir/), a definitiva superação do racismo e das desigualdades raciais implicariam, logicamente, na extinção das necessidades para a vigência da SEPPIR e da própria PNPIR.

Trata-se, portanto, em tese, de políticas de caráter reparador, que não pretenderiam perenizar-se. Uma vez, no entanto, que o racismo e a discriminação racial consolidaram-se e aprofundaram-se ao longo de séculos, como política de Estado, como ferramenta do capital, como herança cultural, radicando-se nas instituições, na cultura, na linguagem e no próprio subconsciente das pessoas, por meio de dezenas de sucessivas gerações, sua superação também implica num esforço de curto, médio e longo prazo, de várias gerações, exigindo, portanto, toda uma estruturação do aparelho de Estado com este objetivo. É nesta perspectiva que deve ser interpretado o texto da proposta 75, do capítulo V - Legislação, da I Conferência Nacional de Promoção da Igualdade Racial (Brasília, 3o/62/7/2005): “...superar seu caráter temporal nos governos..." (http://www.planalto.gov.br/seppir/publicacoes /relatorio_final_conapir.pdf, p. 52). 
Da parte do Programa de Pós-Graduação em Saúde e Ambiente da Universidade Federal do Maranhão e da coordenação de seu Curso de Especialização em Saúde da Mulher Negra, tampouco se pretende contribuir para a cristalização destas categorias "raciais", estabelecidas e impostas pelo processo colonial, quanto menos fundar novas categorias epistemológicas e especialidades no campo da Saúde.

Pretendemos, ao contrário, oferecer respostas que conduzam à superação dessas categorizações, de suas conseqüências no tecido social brasileiro e em suas políticas e serviços (entre os quais, as de saúde): sua superação, no entanto, pressupõe e exige, logicamente, o público reconhecimento e explicitação de suas marcantes presenças e conseqüências, até nossos dias (quando não ainda ostensivamente, de modo mais insidioso e sub-reptício), em nossa sociedade. 